\title{
ALGUNS ASPECTOS JURÍDICOS RELEVANTES SOBRE AS MICROEMPRESAS E EMPRESAS DE PEQUENO PORTE NO BRASIL
}

Sabrina de França Damasceno

Pós-Graduanda em Direito e Processo do Trabalho pelo Damásio Educacional.

Artigo sob orientação do prof. Ms. Felipe dos Reis Barroso (FA7). sabrinafd@hotmail.com

Sumário: Introdução. 1. Conceituação e Histórico das Microempresas e Empresas de Pequeno Porte no Brasil. 2. Características Relevantes das Microempresas e Empresas de Pequeno Porte. Conclusão.

Resumo: Neste artigo, procura-se examinar alguns aspectos jurídicos relevantes das Microempresas e Empresas de Pequeno Porte no Brasil, atualmente regulamentadas pela Lei Complementar 139/11. Faz-se excurso sobre a conceituação e logo após discorre-se sobre as características relevantes, os benefícios tributários, trabalhistas, previdenciários e o acesso às compras governamentais.

Palavras-chave: Pequena Empresa. Conceituação. Características.

\section{INTRODUÇÃO}

Atualmente, a empresa exerce papel de grande importância econômica e social, por ser fonte geradora de riquezas, produtos e serviços, bem como de postos de trabalho. Além disso, estimula o sistema de livre concorrência e compõe relações jurídicas.

Essa importância não se restringe apenas às grandes empresas, mas também às microempresas, às empresas de pequeno porte e aos pequenos empreendedores, por serem fundamentais ao desenvolvimento do país.

A abertura de novos negócios é essencial para o desenvolvimento do país. Entretanto, apenas vontade e coragem não são suficientes para que o empreendimento tenha êxito, visto que para se obter sucesso é fundamental conhecer os aspectos e as fases que envolvem a abertura de um negócio, a legislação aplicada, as oportunidades de mercado, assim como competência, vontade, coragem e afinidade com a atividade. (NUNES, 2009, p. 42).

A pesquisa foi, essencialmente, bibliográfica, tendo sido pesquisados os autores mais relevantes sobre o assunto.

Inicia-se com a conceituação das pequenas empresas. Em seguida, é demonstrado o tratamento diferenciado assegurado a elas. Ao final, são apresentadas as conclusões. 


\section{Conceituação e Histórico das Microempresas e Empresas de Pequeno Porte no Brasil}

A empresa representa, hoje, um dos principais pilares da economia moderna por ser grande fonte de postos de trabalho, geradora de riquezas e rendas tributárias, fornecedora de produtos e serviços em geral, além de motor do sistema da livre concorrência, dentre muitas outras funções.

Tal importância não é atributo apenas das grandes empresas, mas também das microempresas, empresas de pequeno porte, assim como dos pequenos empreendedores.

O tempo tem mostrado que a abertura de novos negócios, baseados na criatividade e no dinamismo do cidadão brasileiro, é fundamental para o desenvolvimento do nosso país. No entanto, apenas vontade e coragem não são suficientes para o sucesso de um empreendimento. O novo empresário precisa conhecer os aspectos e as fases que envolvem a abertura de um negócio, as oportunidades do mercado e, principalmente, a legislação pertinente. Esses fatores, aliados à afinidade com a atividade a ser desenvolvida e à competência gerencial, são fundamentais para o sucesso do negócio (Nunes, 2009, p. 292).

Para os efeitos da $\mathrm{LC} \mathrm{n}^{\circ}$ 123/06, em seu artigo $3^{\circ}$, consideram-se "microempresas ou empresas de pequeno porte a sociedade empresária, a sociedade simples e o empresário a que se refere o art. 966 da Lei ${ }^{\circ}$ 10.406, de 10 de janeiro de 2002, devidamente registrados no Registro de Empresas Mercantis ou no Registro Civil de Pessoas Jurídicas, conforme o caso, desde que:

\footnotetext{
I - no caso da microempresa, aufira, em cada ano-calendário, receita bruta igual ou inferior a R\$360.000,00 (trezentos e sessenta mil reais); e;

II - no caso da empresa de pequeno porte, aufira, em cada ano-calendário, receita bruta superior a R $\$ 360.000,00$ (trezentos e sessenta mil reais) e igual ou inferior a R\$ 3.600.000,00 (três milhões e seiscentos mil reais)."

$\S 4^{\circ}$. Não se inclui no regime diferenciado e favorecido previsto nesta Lei Complementar, para nenhum efeito legal, a pessoa jurídica:

I - de cujo capital participe outra pessoa jurídica;

II - que seja filial, sucursal, agência ou representação, no País, de pessoa jurídica com sede no exterior;

III - de cujo capital participe pessoa física que seja inscrita como empresário ou seja sócia de outra empresa que receba tratamento jurídico diferenciado nos termos desta Lei Complementar, desde que a receita bruta global ultrapasse o limite de que trata o inciso II do caput deste artigo;

IV - cujo titular ou sócio participe com mais de $10 \%$ (dez por cento) do capital de outra empresa não beneficiada por esta Lei Complementar, desde que a receita bruta global ultrapasse o limite de que trata o inciso II do caput deste artigo;

$\mathrm{V}$ - cujo sócio ou titular seja administrador ou equiparado de outra pessoa jurídica com fins lucrativos, desde que a receita bruta global ultrapasse o limite de que trata o inciso II do caput deste artigo;

VI - constituída sob a forma de cooperativas, salvo as de consumo;

VII - que participe do capital de outra pessoa jurídica;

VIII - que exerça atividade de banco comercial, de investimentos e de desenvolvimento, de caixa econômica, de sociedade de crédito, financiamento e investimento ou de crédito imobiliário, de corretora ou de distribuidora de títulos, valores mobiliários e câmbio, de empresa de arrendamento mercantil, de seguros privados e de capitalização ou de previdência complementar;
} 
IX - resultante ou remanescente de cisão ou qualquer outra forma de desmembramento de pessoa jurídica que tenha ocorrido em um dos 5 (cinco) anos-calendário anteriores; $\mathrm{X}$ - constituída sob a forma de sociedade por ações.

Para fruir os benefícios do Estatuto Nacional da Microempresa e de Empresa de Pequeno Porte, é indispensável estar devidamente registrado no Registro de Empresas Mercantis; obviamente, não há do que se falar em Registro Civil de Pessoas Jurídicas, nem mesmo Registro Civil de Pessoas Naturais, o que não atende, em nada, à regra do artigo $3^{\circ}$. Justamente por isso, o profissional autônomo não se beneficiará desta Lei Complementar 123/06; só o empresário, isto é, o titular de empresa, devida e regularmente registrado na respectiva Junta Comercial (Mamede, 2007, p.13).

No intuito de proteger as empresas, comerciais, industriais ou civis, de regulamentos e portarias a que se submetiam tanto os pequenos empreendimentos como as grandes empresas, é que no ano de 1979, o Brasil inicia um processo de desburocratização. Isso se deu porque, ou as microempresas optavam pela sonegação de impostos e fraude administrativa, ou estavam fadadas ao insucesso.

Nesse sentido, houve a sistematização e a uniformização das normas que versavam sobre as microempresas, já que até então somente existiam leis esparsas referentes a casos específicos.

Foi então que, em 1984, surgiu o primeiro Estatuto da Microempresa (Lei 7.256/84) que trazia alguns benefícios tributários, administrativos, trabalhistas, previdenciários, creditícios e de desenvolvimento empresarial para os microempresários. Essa lei teve a vigência de quase uma década. De lá para os dias atuais, houve a criação de uma sucessão de estatutos que tratam dos micro e pequenos empreendimentos, mas seus sucessores aproveitavam sempre sua estrutura, modificando apenas o conteúdo.

Em 1988, os ideais consagrados no referido Estatuto da Microempresa são absorvidos pelo legislador constituinte, e a Carta Magna passa a considerar tratamento favorecido para os pequenos empreendedores como um dos princípios gerais da atividade econômica (art. 170, IX).

Posteriormente, foi editada a Lei $n^{\circ} 8.864 / 94$, que criava o Estatuto de Microempresa e da Empresa de Pequeno Porte. A grande inovação desta lei foi que ela trouxe a figura da empresa de pequeno porte, visando tornar mais lento e gradual o caminho do pequeno empreendedor do regime jurídico-empresarial simplificado para o regime jurídico-empresarial geral.

Pouco tempo depois, surge a Lei $n^{\circ}$ 9.317/96, que instituiu o SIMPLES (sistema integrado de pagamento de impostos e contribuições das microempresas e empresas de pequeno porte). Essa prerrogativa consiste na possibilidade do pagamento de vários tributos mediante um recolhimento único mensal, o que, a um só tempo, diminui a carga tributária e elimina certas exigências burocráticas decorrentes da arrecadação fiscal.

Passados mais alguns anos, o Brasil edita a Lei no 9.841/99, que revoga as leis anteriores sobre o tema e institui o novo Estatuto da ME e EPP, com exceção à lei do SIMPLES, que continua em vigor.

Mais adiante, o Código Civil de 2002 determina em seu art. 970 matéria sobre o assunto. Alguns anos depois, a Emenda Constitucional n ${ }^{\circ} 42$, batizada de Reforma Tributária, determinou que a definição de tratamento favorecido e simplificado para as MEs e EPPs fosse feita por lei complementar (art.146, inciso III, alínea "d", da CF/88).

Seguindo a nova disposição constitucional, foi editada a Lei Complementar $n^{\circ}$ 123/06, batizada de Lei Geral das Micro e Pequenas Empresas, que passou a ser o nosso novo Estatuto das MEs e EPPs. 
Atualmente, está em vigor a Lei Complementar $n^{0} 139$, de 10 de novembro de 2011, que altera dispositivos da Lei Complementar $n^{\circ} 123$, de 14 de dezembro de 2006 , e dá outras providências.

\section{Características Relevantes das Microempresas e Empresas de Pequeno Porte}

\subsection{Benefícios Tributários}

Segundo Tomazette (2011, p. 55-56), é bem provável que a circunstância mais importante para a tomada de decisão do enquadramento como microempresa e empresa de pequeno porte é o tratamento tributário diferenciado, que abrange, essencialmente, um regime especial unificado de arrecadação de tributos e contribuições devidas. A intenção é tornar mais simples o recolhimento tributário, fazendo-o de forma unificada e não de forma repartida entre os vários tributos. Esse pensamento de simplificação é claro no próprio nome adotado pelo sistema, SIMPLES Nacional.

O art. 13, da Lei Complementar 123/06, dispõe que o SIMPLES Nacional envolve a arrecadação conjunta, em um único documento, dos valores que seriam pagos de forma individualizada a título de:

Imposto de Renda Pessoa Jurídica (IRPJ), Imposto sobre Produtos Industrializados (IPI), Contribuição Social sobre o Lucro Líquido (CSLL), Contribuição para o Financiamento da Seguridade Social (COFINS), PIS/PASEP, Imposto sobre Operações Relativas à Circulação de Mercadorias e sobre Prestações de Serviços de Transporte Interestadual e Intermunicipal e de Comunicação (ICMS), Imposto sobre Serviços de Qualquer Natureza (ISS) e a contribuição previdenciária patronal incidente sobre a folha de salários, com ressalvas em relação a algumas prestadoras de serviços.

A junção de todos esses recolhimentos em um único documento efetivamente mostra uma simplificação das obrigações e provável diminuição de valores a pagar. Não obstante, em certos casos, a própria Lei Complementar 123/06 estabelece o recolhimento separado de certos tributos e contribuições.

Desse modo, a escolha pelo SIMPLES Nacional não afasta o dever de recolhimento em separado dos tributos referidos no art. $13, \S 1^{\circ}$, da referida lei, como o Imposto sobre Operações Financeiras, o Imposto de Importação, o Imposto de Exportação, o Imposto Territorial Rural, o IR relativo aos rendimentos ou ganhos líquidos auferidos em aplicações de renda fixa ou variável, e relativo a ganhos de capital auferidos na alienação de bens do ativo permanente, a contribuição para o FGTS, a contribuição previdenciária relativa aos trabalhadores, a contribuição previdenciária relativa à pessoa do empresário, o Imposto de Renda relativo aos pagamentos efetuados, a Contribuição para o PIS/PASEP, COFINS e IPI incidentes na importação de bens e serviços e demais tributos de competência da União, dos Estados, do Distrito Federal (IPVA) ou dos Municípios (IPTU).

Afora isso, existe também a obrigação de recolhimento do ICMS nos casos de substituição tributária, como também o devido por terceiro, cujo recolhimento fica sob responsabilidade do enquadrado; o ICMS sobre petróleo, incluindo lubrificantes e combustíveis líquidos e gasosos dele derivados; energia elétrica, quando não reservada à comercialização ou industrialização; e também no desembaraço aduaneiro, na aquisição ou conservação em estoque de mercadoria desacobertada de documento fiscal, na operação ou prestação desacobertada de documento fiscal, nas operações com mercadorias sujeitas ao regime de antecipação do 
recolhimento do imposto. De maneira semelhante, também existe o dever de recolhimento do ISS nos casos de substituição tributária e na importação de serviços (TOMAZETTE, 2011, p. 56).

As pequenas empresas optantes pelo SIMPLES Nacional ficam isentas do pagamento das outras contribuições estabelecidas pela União, inclusive as contribuições para as entidades privadas de serviço social e de formação profissional sujeitas ao sistema sindical (SESC, SENAC, SESI, SENAI). Por outro lado, as que preferirem o sistema do SIMPLES Nacional não podem se atribuir nem ceder créditos referentes a impostos (ICMS, IPI) ou contribuições (COFINS), como dispõe a Lei Complementar 123/06, art. 23: “As microempresas e as empresas de pequeno porte optantes pelo Simples Nacional não farão jus à apropriação nem transferirão créditos relativos a impostos ou contribuições abrangidos pelo Simples Nacional". Eles também não poderão aproveitar ou destinar qualquer valor a título de incentivos fiscais, conforme previsto na Lei Complementar 123/06, art. 24: "As microempresas e as empresas de pequeno porte optantes pelo Simples Nacional não poderão utilizar ou destinar qualquer valor a título de incentivo fiscal".

De certo modo, a grande inovação que decorreu da $\mathrm{LC} \mathrm{n}^{0} 123 / 06$ foi a criação do SIMPLES NACIONAL, um sistema unificado de recolhimento mensal de impostos e contribuições federais, estaduais e municipais, elaborado de acordo com o disposto do parágrafo único, do artigo 146, alínea "d”, da Constituição Federal:

\footnotetext{
Parágrafo único. A lei complementar de que trata o inciso III, d, também poderá instituir um regime único de arrecadação dos impostos e contribuições da União, dos Estados, do Distrito Federal e dos Municípios, observado que:

I - será opcional para o contribuinte;

II - poderão ser estabelecidas condições de enquadramento diferenciadas por Estado;

III - o recolhimento será unificado e centralizado e a distribuição da parcela de recursos pertencentes aos respectivos entes federados será imediata, vedada qualquer retenção ou condicionamento;

IV - a arrecadação, a fiscalização e a cobrança poderão ser compartilhadas pelos entes federados, adotado cadastro nacional único de contribuintes.
}

Com isso, as pequenas empresas optantes pelo SIMPLES NACIONAL recolhem mensalmente, de forma unificada e centralizada, todos esses tributos federais, estaduais e municipais, ficando a União (através da Receita Federal) responsável pela distribuição imediata da quantia relativa aos devidos entes (Estados e Municípios), sendo proibido guardar ou condicionar o repasse desses valores sob qualquer pretexto. (RAMOS, 2009, p. 180).

\subsection{Benefícios Trabalhistas}

Como se não bastasse a burocracia inseparável das circunstâncias tributárias, sabe-se que, do mesmo modo, os empresários são forçados a atender a uma enorme burocracia relativa a seus compromissos na qualidade de empregador. Essas formalidades têm um custo alto para o empresário, o que terminou criando a necessidade de um tratamento diferenciado dessas circunstâncias para as microempresas e empresas de pequeno porte, em atendimento à Constituição Federal. (TOMAZETTE, 2011, p. 57-58).

Assim, quem se enquadra como microempresa ou empresa de pequeno porte fica dispensado pela Lei Complementar 123/06, art.51:

da fixação de quadro de trabalho em suas dependências; da anotação das férias dos empregados nos respectivos livros ou fichas de registro; de empregar e matricular seus aprendizes nos cursos dos Serviços Nacionais de Aprendizagem; da posse do livro intitulado 'Inspeção do Trabalho'; e de comunicar ao Ministério do Trabalho e Emprego a concessão de férias coletivas. 
Segundo Tomazete (2008, p. 58), contudo, essa simplificação dos deveres trabalhistas é parcial, não compreendendo outros deveres como:

\begin{abstract}
a anotação na CTPS dos seus empregados, o arquivamento dos documentos comprobatórios de cumprimento das obrigações trabalhistas e previdenciárias, enquanto não prescreverem essas obrigações, a apresentação da GFIP - Guia de Recolhimento do Fundo de Garantia do Tempo de Serviço e Informações à Previdência Social -, apresentação das Relações Anuais de Empregados e da Relação Anual de Informações Sociais (RAIS) e do Cadastro Geral de Empregados e Desempregados (CAGED).
\end{abstract}

Ademais, no que concerne aos aspectos trabalhista, sanitário, ambiental e de segurança, é disposto na legislação que a fiscalização das microempresas e empresas de pequeno porte deverá possuir natureza prioritariamente orientadora, quando a atividade ou situação, por sua essência, proceder grau de risco compatível com esse modo de atuar. (MAMEDE, 2007, p. 116).

Feitas essas observações, passa-se à análise das regras trazidas pela Lei Geral. Segundo o seu art. 50: “as microempresas e as empresas de pequeno porte serão estimuladas pelo poder público e pelos Serviços Sociais Autônomos a formar consórcios para acesso a serviços especializados em segurança e medicina do trabalho". (Redação dada pela Lei Complementar $\mathrm{n}^{\mathrm{o}} 127$, de 2007).

O referido artigo se refere a mais uma norma programática da lei, que somente traça diretrizes gerais de atuação ao poder público com a finalidade de fazer efetivar os objetivos da lei. O dispositivo, além de propagar uma determinação ao Poder Executivo, confere a ele, para exercício desse mister, o privilégio de instrumentalizar a estimulação pretendida por meio de normas legais e até mesmo infralegais. Desse modo, cabe ao Poder Executivo, por meio de suas Secretarias e Ministérios, editar Portarias, Resoluções, Instruções Normativas, entre outros atos normativos secundários, com a finalidade de tornar menos burocrático o acesso aos serviços de medicina e segurança do trabalho por parte dos microempresários e dos empresários de pequeno porte. (RAMOS, 2009, p. 166).

Afora isso, processualmente é autorizado que o empregador de microempresa ou de empresa de pequeno porte não compareça por si mesmo às audiências, tendo a possibilidade de fazer-se substituir ou representar perante a Justiça do Trabalho por terceiros que tenham conhecimento dos fatos, mesmo que não possuam vínculo trabalhista ou societário com o empresário enquadrado como microempresa ou empresa de pequeno porte. (TOMAZETTE, 2011, p. 58).

É válido ressaltar o fato de que a Lei Geral conservou o já conhecido critério da "dupla visita”, em regra, para lavratura de autos de infração, dispondo, no art. 55, §1 ${ }^{\circ}$, que:

\footnotetext{
será observado o critério de dupla visita para lavratura de autos de infração, salvo quando for constatada infração por falta de registro de empregado ou anotação de Carteira de Trabalho e Previdência Social-CTPS, ou, ainda, na ocorrência de reincidência, fraude, resistência ou embaraço à fiscalização.
}

Observe-se que a Lei Geral, em contraposição ao que fazia o Estatuto anterior, não limitou a aplicação do critério da "dupla visita" apenas à fiscalização trabalhista, o que nos leva à interpretação de que tal critério deverá ser aplicado no âmbito de todas as fiscalizações, mencionado no caput do art. 55, ou seja, a trabalhista, metrológica, sanitária, ambiental e de segurança. Decorre do princípio que constatado o descumprimento, por parte de uma ME ou EPP, de determinada obrigação numa dessas áreas, os fiscais devem inicialmente orientar o microempresário ou empresário de pequeno porte, somente devendo autuá-lo, regra geral, em caso de reincidência. Resumindo, "a fiscalização deve visitar as MEs e EPPs para instruí-las, e não para sancioná-las. Somente quando da constatação ulterior do desrespeito à orientação, terá lugar o apenamento". (RAMOS, 2009, p. 169). 
Dando aplicação à ideia geral de simplificação das obrigações, o art. 51 da Lei Geral dispõe, diretamente, sobre a desobrigação do cumprimento de algumas obrigações acessórias previstas na Consolidação das Leis do Trabalho, tais como a manutenção de livro de inspeção do trabalho (art. 628, $\S 1^{\circ}$, da CLT) e a anotação de férias em livro ou ficha (art. 135, $\S 2^{\circ}$, da CLT) (RAMOS, 2009, p. 166). No que concerne às regras trabalhistas, Ramos (2009, p. 165) afirma que:

\begin{abstract}
a Lei Geral, embora tenha inovado em alguns pontos em relação ao Estatuto anterior, ainda foi muito tímida, mais uma vez ignorando a patente realidade de que muitos microempresários e empresários de pequeno porte não suportam os altos custos da folha salarial, o que faz preferir, na maioria das vezes, a contratação informal. Ocorre que, futuramente, esses contratos de trabalho informais serão reconhecidos pela Justiça do Trabalho, que condenará esses pequenos empreendedores a pagar altas indenizações. É assim que ocorre na prática, e por isso a Justiça do Trabalho é vista por boa parte do meio empresarial como uma das grandes inimigas do empreendedorismo. Cabia ao legislador ter previsto normas mais eficazes para combater essa realidade prática, desonerando a folha salarial das MEs e EPPs, por exemplo, o que estimularia a contratação regular e aumentaria os índices de empregos formais no Brasil. Tomara que essas regras ainda venham um dia, quem sabe no tão esperado momento em que o Congresso Nacional aprove a Reforma Trabalhista.
\end{abstract}

Como se percebe, a doutrina reconhece a evolução que decorre das disposições da Lei Complementar 123/06, mas propõe que as vantagens ainda sejam ampliadas.

\title{
2.3 Benefícios Previdenciários
}

Afora isso, ela garante aos pequenos empresários a desobrigação:

do recolhimento das contribuições sindicais de que trata a Seção I do Capítulo III do Título V da Consolidação das Leis do Trabalho (CLT), das contribuições de interesse das entidades privadas de serviço social e de formação profissional vinculadas ao sistema sindical (terceiros), das contribuições para o salário-educação e das contribuições instituídas pela Lei Complementar 110/01. (TOMAZETTE, 2011, p. 59).

Semelhantes isenções valem por, no máximo, três anos. A intenção aqui é estimular a realização, segundo as formalidades, das atividades do pequeno empresário. Ressalte-se que, repetindo o que prevê a Lei Complementar 123/06, em seu artigo 52:

\begin{abstract}
a anotação na CTPS dos seus empregados, o arquivamento dos documentos comprobatórios de cumprimento das obrigações trabalhistas e previdenciárias, enquanto não prescreverem essas obrigações, a apresentação da GFIP - Guia de Recolhimento do Fundo de Garantia do Tempo de Serviço e Informações à Previdência Social -, apresentação das Relações Anuais de Empregados e da Relação Anual de Informações Sociais (RAIS) e do Cadastro Geral de Empregados e Desempregados (CAGED).
\end{abstract}

Por esse aspecto, vale salientar que a simplificação do regime previdenciário aplicável às pequenas empresas não tem um resultado satisfatório perante o que consta no artigo 179 da Carta Magna, uma vez que a simples dispensa de algumas obrigações acessórias é ineficaz para dar total efetividade à norma encartada no referido artigo. $\mathrm{O}$ ideal seria estabelecer um regime jurídico previdenciário verdadeiramente especial para as pequenas empresas.

\subsection{Benefícios no Acesso às Compras Governamentais}

De acordo com Tomazette (2008, p. 59), tendo em vista a ordem constitucional de se conferir tratamento diferenciado às microempresas e empresas de pequeno porte, a Lei Complementar 123/06 assegura um tratamento diferenciado no que diz respeito ao acesso ao mercado, somente para as aquisições públicas, uma vez que não poderia haver imposição de 
regras diferenciadas de contratação para os particulares. Essas regras tentam tornar mais simples e incentivar a atuação de microempresas e de empresas de pequeno porte nessas situações.

$\mathrm{O}$ art. 44 da Lei Complementar 123/06 dispõe que "nas licitações será assegurada, como critério de desempate, preferência de contratação para as microempresas e empresas de pequeno porte". A norma em questão inova bastante, mas precisa ser explicada com mais precisão.

De início, como uma regra geral para todas as licitações, a Lei Complementar 123/06 (art. 42) determina que nas licitações públicas a comprovação de regularidade fiscal das microempresas e empresas de pequeno porte apenas será exigida quando da assinatura do contrato. Torna mais simples, assim, o procedimento para as microempresas e empresas de pequeno porte participarem de certames licitatórios, não havendo a necessidade de comprovação da regularidade fiscal desde o início do certame.

Todavia, é proibida a inabilitação da ME e da EPP se sua documentação contiver qualquer restrição no que atinge à regularidade fiscal, ocorrência em que será garantido o prazo de dois dias úteis, cujo termo inicial equivale ao momento em que o proponente for anunciado o vencedor do certame, prorrogáveis pelo mesmo período, para a regularização da documentação. Não se desobriga a regularidade fiscal, apenas se dá mais prazo para a comprovação dessa regularidade fiscal. (NOHARA, 2007, p. 290).

Nessa circunstância, entende-se por empate, de acordo com a lei, as situações em que as propostas apresentadas pelas microempresas e empresas de pequeno porte sejam iguais ou até $10 \%$ (dez por cento) superiores à proposta mais bem classificada. O que ocorre não é precisamente um empate, mas uma proximidade entre os preços ofertados, que, nesse caso, será obrigado a ser tratado como empate e haverá preferência para a contratação de uma ME ou EPP. (NOHARA, 2007, p. 293).

Ocorrendo esse "empate" (Lei Complementar 123/06, art.45), a ME ou EPP melhor classificada poderá apresentar uma nova proposta por preço inferior àquela vencedora da disputa. Neste caso, será conferido o objeto da disputa a quem apresentar essa proposta por preço inferior. Caso a ME ou EPP mais bem classificada não apresente a proposta, serão chamadas as seguintes, que se enquadrem na situação de empate já descrita. Em caso de igualdade entre as propostas, haverá um sorteio para estabelecer qual delas poderá apresentar primeiro a proposta de adjudicação do objeto da disputa. Se nenhuma ME ou EPP apresentar a proposta, o objeto será conferido ao vencedor inicial. Tal sistema de proposta por preço inferior para adjudicação não se aplica se a proposta inicialmente vencedora do certame já for de uma ME ou EPP.

$\mathrm{Na}$ hipótese de pregão, entende-se que existe um empate se o preço ofertado por uma ME ou EPP for até 5\% superior ao lance vencedor (Lei Complementar 123/06, art. 44, $\S 2^{\circ}$ ). Dada a particularidade do sistema de lances, a microempresa ou empresa de pequeno porte mais bem classificada será chamada para apresentar nova proposta no prazo máximo de 5 (cinco) minutos após o encerramento dos lances, sob pena de preclusão (Lei Complementar $123 / 06$, art. $45, \S 3^{\circ}$ ). Apesar de a regra não ser expressamente dirigida ao caso do pregão, é certo que essa possibilidade de apresentação e nova proposta não será admissível se o vencedor já for uma ME ou EPP.

Em geral, tal sistema favorece a entidade contratante, que poderá obter um preço ainda mais alto, mas diminui a efetividade da concorrência nas licitações. Se as empresas de pequeno porte tiverem condições de arcar com as propostas, elas sempre ganharão nessas disputas. Não haveria qualquer inconstitucionalidade neste particular, dada a clara disposição constitucional de tratamento diferenciado para as pequenas empresas. (TOMAZETTE, 2011, p. 60). 
Afora esse tratamento especial obrigatório, a União, os Estados, o Distrito Federal e os Municípios poderão outorgar tratamento diferenciado nas licitações às MEs e EPPs, tornando objetiva a promoção do desenvolvimento econômico e social na esfera municipal e regional, a ampliação da eficiência das políticas públicas e o incentivo à inovação tecnológica. Semelhante possibilidade depende, todavia, de regramento legal específico a ser editado. (TOMAZETTE, 2011, p. 60).

A administração pública pode realizar procedimento licitatório com condições especiais, beneficiando as microempresas e empresas de pequeno porte, que necessariamente terão participação no resultado do certame diretamente ou por meio de uma subcontratação (Lei Complementar 123/06, art. 48). Assim, poderá haver certame destinado exclusivamente à participação de microempresas e empresas de pequeno porte nas contratações cujo valor seja até R \$ 80.000,00 (oitenta mil reais), ou em que seja exigida dos licitantes a subcontratação de microempresa ou de empresa de pequeno porte, desde que o percentual máximo do objeto a ser subcontratado não exceda a 30\% (trinta por cento) do total licitado; ou, ainda, em que se estabeleça cota de até $25 \%$ (vinte e cinco por cento) do objeto para a contratação de microempresa e empresas de pequeno porte, em certames para a aquisição de bens e serviços de natureza divisível.

Para esses casos, nem todas as licitações recebem esse tratamento especial. De acordo com o previsto no $\S 1^{\circ}$ do artigo 48: “o valor licitado por meio do disposto neste artigo não poderá exceder a $25 \%$ do total licitado em cada ano civil". Além disso, tem que haver previsão clara dos requisitos no instrumento convocatório da licitação. Também é exigida a obediência à regra de que não haja um número inferior a três fornecedores competitivos sediados no local ou regionalmente e aptos a concorrer. (NOHARA, 2007, p. 309).

Ademais, é garantido que o interesse público deve se sobressair sobre o interesse particular. Então, se o tratamento diferenciado e simplificado para as pequenas empresas não trouxer vantagem para a administração pública ou for causador de prejuízo ao conjunto ou complexo do objeto a ser contratado, não poderá ser realizado o procedimento nessas condições especiais. Da mesma forma, se a licitação for inexigível ou dispensável não há motivo de se buscar esse tratamento diferenciado, pois nessas situações será difícil ou ao menos não será razoável obrigar tais limites de tratamento preferencial. (TOMAZETTE, 2011, p. 61).

\section{Conclusão}

O questionamento sobre se é sempre vantajoso ou existem desvantagens a serem enfrentadas ao abrir uma microempresa ou empresa de pequeno porte motivou o interesse na elaboração do trabalho.

Constatou-se que inúmeras vantagens são atribuídas às pequenas empresas, o que as torna altamente competitivas. Contudo, indaga-se por que mesmo com os benefícios tributários, trabalhistas e previdenciários favorecendo as microempresas e empresas de pequeno porte, ainda existem milhares delas na informalidade?

Sabe-se que a Lei Complementar 123/06 e, posteriormente, a Lei Complementar 139/11, trouxeram uma vasta inovação e favorecimento para as pequenas empresas, mas ainda assim não é o suficiente para que elas se mantenham no mercado. A carga tributária continua alta, gerando uma competitividade desigual entre elas e as médias e grandes empresas. Por isso, dentre outros motivos, muitas pequenas empresas ainda vivem na informalidade, e estas não gozarão de todos os benefícios trazidos pela referida Lei. 
ALGUNS ASPECTOS JURÍDICOS RELEVANTES SOBRE AS MICROEMPRESAS E EMPRESAS

DE PEQUENO PORTE NO BRASIL

\section{REFERÊNCIAS}

ARNOLDI, Paulo Roberto Colombo. Revista Nacional de Direito e Jurisprudência. Brasil, n 77 , maio 2006.

BARROSO, Felipe dos Reis. Manual de formatação de monografia jurídica. Fortaleza: Book, 2006.

BONAVIDES, Paulo; MIRANDA, Jorge; AGRA, Walber de Moura. Comentários à Constituição Federal de 1988. Rio de Janeiro: Forense, 2009.

BRASIL. Constituição (1998). Constituição da República Federativa do Brasil. Brasília: DF, Senado, 1988.

ECO, Umberto. Como se faz uma tese. 12. ed. São Paulo: Perspectiva, 1995.

FIGUEIREDO, Ana Luiza Ferrete Garcia de. Situação jurídica das microempresas e empresas de pequeno porte no Brasil. São Paulo: Saraiva, 2005.

FIÚZA, Ricardo. Novo Código Civil comentado. 5. ed. São Paulo: Saraiva, 2006.

MAMEDE, Gladston. Direito empresarial brasileiro: empresa e atuação empresarial. 2. ed. São Paulo: Atlas, 2007. v. 1.

MAMEDE, Gladston; MACHADO SEGUNDO, H. de B.; NOHARA, I. P.; MARTINS, S. P. Comentários ao Estatuto Nacional da MICROEMPRESA e da Empresa de PEQUENO PORTE. São Paulo: Atlas, 2007.

NUNES, Renata Gomes. “Microempreendedor individual”. Revista Jurídica Consulex. São Paulo, ano XIII, n 292, 2009.

RAMOS, André Luiz Santa Cruz. Curso de direito empresarial. 3. ed. Bahia: JusPODIVM, 2009.

SILVA, José Alberto da. Questões jurídicas e tributárias envolvendo a pequena empresa. Fortaleza, 2010, 45 p. Monografia (Graduação) - Fa7, 2010.

TOMAZETTE, Marlon. Curso de direito empresarial: teoria geral e direito societário. São Paulo: Atlas, 2011. v. 1.

\section{SOME RELEVANT LEGAL ASPECTS ON THE MICRO AND SMALL ENTERPRISES IN BRAZIL}

Abstract: This article seeks to examine some relevant legal aspects of Micro and Small Enterprises in Brazil, currently regulated by the Complementary Law 139/11.

Keywords: Small Business. Regulation. Characteristics.

Data de recebimento: jun/2013 - Data de aprovação: jul/2013 